\title{
DIFERENTES ENTRE IGUALES: EL PAPEL DEL ARTE RUPESTRE EN LA REAFIRMACIÓN DE IDENTIDADES EN EL SUR DEL VALLE DE GUASAPAMPA (CÓRDOBA, ARGENTINA)
}

\author{
EQUAL BUT DIFFERENT: THE ROLE OF ROCK ART IN THE REASSERTION OF \\ IDENTITIES IN THE SOUTHERN GUASAPAMPA VALLEY (CÓRDOBA, ARGENTINA)
}

ANDREA RECALDE*

El objetivo de este trabajo es presentar un análisis de las representaciones rupestres documentadas en el valle de Guasapampa, emplazado en el corredor oeste de las Sierras Grandes (provincia de Córdoba, Argentina), que fue ocupado fundamentalmente durante la época estival desde ca. 1300 al 360 AP. Para tal fin proponemos que, tanto la selección de motivos, los patrones constructivos de las figuras y sus asociaciones, como las condiciones de invisibilidad de soportes y paneles, participaban de las estrategias sociales que procuraban reforzar los lazos de identidad y pertenencia de las diferentes unidades familiares, al tiempo que buscaban disminuir el posible conflicto entre los distintos grupos que explotaban y construían un paisaje compartido.

Palabras clave: arte rupestre, identidades, invisibilidad, unidades familiares, ocupaciones estacionales

This work presents an analysis of rock art images documented in the Guasapampa Valley, located in the western ranges of the Sierras Grandes in the province of Córdoba, Argentina, which was occupied primarily during the summer months from ca. 1300 to 360 BP. To this end we propose that the choice of motifs, patterns of construction of figures and their associations, and the invisibility of the media and panels played a part in social strategies that sought to reinforce ties of identity and belonging of different family units, while at the same time seeking to minimize potential conflict among different groups that made use of and constructed this shared landscape.

Key words: rock art, identities, invisibility, family units, seasonal occupations

\section{INTRODUCCIÓN}

En este artículo presentamos un análisis de los paneles con motivos pintados y grabados de la sección sur del valle de Guasapampa (provincia de Córdoba, Argentina) (fig. 1). La información recuperada en la microrregión ha dado lugar a preguntas sobre la incidencia de las representaciones rupestres en la construcción y la afirmación de la identidad de los grupos que las ejecutaron, a partir de la interacción cotidiana de las personas con este elemento de la cultura material. Para tal fin, las nociones de paisaje, materialidad y lugar conforman el punto de partida para comprender las relaciones y vínculos entre las personas y los grupos.

En primer lugar, el paisaje se conceptualiza en tanto constructo social, es decir, como un espacio socialmente producido y en esencia reproducido que, necesariamente, implica una dialéctica entre el paisaje físico y el humano (Soja 1985; Piazzini 2006). Por lo tanto, necesitamos pensarlo como una entidad experimentada en forma constante a partir de las vivencias que los grupos tienen con el entorno, vivencias que transforman al espacio en un paisaje social y culturalmente construido (p. e., Bender 1993; Ingold 1993; Criado Boado 1996). En otros términos, los paisajes son percibidos y conceptualizados por medio y a partir de las vivencias y prácticas cotidianas (Ingold 1992: 45), de la misma manera que

* Andrea Recalde, Conicet, Cátedra de Prehistoria y Arqueología, Universidad Nacional de Córdoba, San José de Calazans s/n, Barrio Q2, Mendiolaza, Córdoba, CP (5107), Argentina, email: recaldema@yahoo.com.ar 


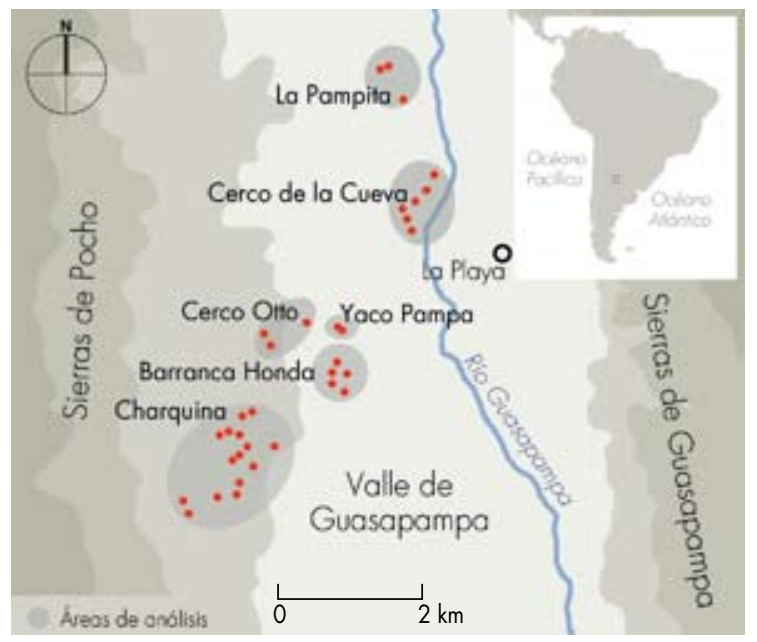

Figura 1. Localización de las áreas en las que se distribuyen los paneles con representaciones.

Figure 1. Location of areas containing panels with images.

estos ámbitos significados socialmente constituyen el marco para la constitución de las dinámicas sociales.

Esta visión abandona el posicionamiento en uno u otro extremo de la dicotomía, forzada e irreal, entre naturaleza y cultura, es decir, modifica la imagen occidental de la naturaleza como algo a ser domesticado, controlado y, en tanto externa a las actividades humanas, analizado como un elemento medible, cuantificable y mensurable (Barbero 2006; Piazzini 2006). Este replanteo del paisaje permite también resignificar el papel de la materialidad en la vida social, dado que la cultura ya no es sólo una respuesta a las características ambientales, sino, por el contrario, los objetos son elementos activos en la construcción del entorno, por cuanto conforman el resultado y el medio para la (re)producción y la negociación de los vínculos entre los individuos (Acuto 1999; Piazzini 2006).

Los objetos, como fenómenos sociales, constituyen la materialización parcial de la vida social y conforman lugares acotados del espacio, que en términos de Augé (1992) son definidos como lugares antropológicos. En este sentido, se entiende que un rasgo natural (Criado Boado 1995), una estructura arquitectónica (Bender 1993) o un objeto específico, como el arte rupestre (Santos Estévez \& Criado Boado 1998), participan en la construcción de lugares, esto es, son significados como puntos concretos de la objetivación de lo social y de las relaciones entre las personas o los grupos. Estos puntos significativos del paisaje están caracterizados por densidades disímiles de experiencias que pueden estar asociadas a diversos tipos de actividades en momentos o ciclos estacionales diferentes (Jones
1998). Así, los lugares no conforman sólo espacios de habitación u ocupación en los cuales se desarrollan las tareas cotidianas, las labores domésticas o las vinculadas con las acciones rituales, sino que, por el contrario, están definidos por y a partir de las actividades realizadas en ellos (Jones 1998).

En este sentido, la reocupación de un lugar por miembros de un mismo grupo que comparten una historia en común, puede definirlo como un lugar de identidad (Augé 1992). Es preciso puntualizar que esta noción no implica una asociación automática entre el espacio y la cultura, dado que la identidad no está atada de manera directa a los espacios físicos (Anschuetz et al. 2001: 179). La identidad, que se origina en un sentido de pertenencia y a la vez de diferenciación del otro, se construye a partir de la interacción entre las personas sobre diferencias socialmente sancionadas como significativas (Díaz Andreu \& Lucy 2005). Es por esto que no se agota sólo en las consideraciones étnicas, entendidas en términos de similitud cultural, sino que puede estar relacionada con múltiples identidades sociales.

La identidad no tiene una condición natural o inherente, definida de antemano, como tampoco tiene una condición estática y permanente o, en palabras de Bauman (2005: 32), "con garantía de por vida", sino que está sujeta a una constante negociación y, en consecuencia, puede ser modificada e incluso revocada. Es así que a partir de la construcción cotidiana de los lugares sus ocupantes reproducen y reconocen "señales" o elementos de la materialidad que permiten reforzar y negociar el sentido de pertenencia y fortalecer los lazos de relación con los pares. El diseño de la cultura material, que está activamente involucrado en la práctica social, puede ser significado en el interior de un grupo para expresar género, estatus, pertenencia a una unidad familiar, edad y, con relación a lo expuesto, el objetivo no tiene que estar siempre a favor de la integración, sino que puede informar y reforzar la diferenciación de grupos como segmentos constitutivos de una sociedad mayor.

Estos mensajes se realizan a partir de códigos compartidos, que pueden comunicar información para los otros o para un nosotros, y en los cuales entran en juego las estrategias de demarcaciones del paisaje, la activación de la memoria colectiva y la identificación de los miembros de un grupo particular (Aschero 2007). En este contexto la acción de ejecutar motivos pintados o grabados sobre una superficie rocosa establece las condiciones para la conformación de un lugar en el paisaje. En consecuencia, la reiteración en la ejecución de motivos o temas, diseños y uso del panel actúan como recursos simbólicos que reafirman los aspectos distintivos de cada grupo, al sostener la continuidad de una práctica significativa para las personas que 
construyen, negocian y fortalecen cotidianamente su filiación y cohesión.

El objetivo de este trabajo, a partir del ordenamiento de los datos en base a variables de análisis, es establecer tanto la estandarización, entendida como la adopción de ciertos elementos o rasgos que son compartidos y reproducidos en el tiempo (Martel \& Aschero 2007), como las especificidades presentes en la variabilidad de los paneles de Guasapampa. Entre las variables consideradas abarcamos motivos y cánones de las representaciones junto a un universo más amplio en el que participan otras, como las asociaciones temáticas y las condiciones de visibilidad e invisibilidad documentadas entre los paneles de la microrregión del oeste de Córdoba.

\section{PAISAJE Y MATERIALIDAD EN GUASAPAMPA}

\section{Particularidades de la distribución de paneles}

La zona objeto de estudio se ubica en la región genéricamente conocida como Sierras Centrales, la cual se extiende a lo largo de más de $600 \mathrm{~km}$, con rumbo general norte-sur, entre los 29 30' y 33030' de Latitud Sur y 6340' y 65²0' de Longitud Oeste. Está conformada por tres conjuntos orográficos separados por valles longitudinales: las Sierras Chicas emplazadas al oriente; las Sierras Grandes, que constituyen el cordón que registra las mayores alturas (p. e., Cerro Champaquí $2.790 \mathrm{~m}$ ) y finalmente el grupo occidental en el límite oeste de la provincia de Córdoba. Es específicamente en el marco de esta última formación donde se localiza la microrregión del valle de Guasapampa.

Guasapampa, emplazado a $600 \mathrm{msnm}$, es un pequeño valle intermontano ubicado entre las Sierras de Pocho al oeste y las de Serrezuela y Guasapampa al este (fig. 1). Podemos dividirlo en dos secciones, norte y sur, a partir de la estrecha quebrada por la cual discurre encajonado el río Guasapampa. Está dominado por un ambiente de Chaco Serrano, con algunos rasgos propios del Chaco Seco (Demaio et al. 2002), caracterizado por su gran aridez debido a las escasas precipitaciones, que oscilan entre los 400 y 500 mm, concentradas en época estival. A estas condiciones de escasa humedad se suma la elevada evapotranspiración, que genera un alto déficit del recurso hídrico en la zona, estimado en unos $300 \mathrm{~mm}$ anuales. Sin embargo, el ambiente chaqueño ofrece algunas especies vegetales de significativa importancia económica para los grupos aborígenes que ocuparon el área, como algarrobo (Prosopis sp.), chañar (Geoffroea decorticans) y piquillín (Condalia microphylla), entre otros.
Presentamos los trabajos arqueológicos que desarrollamos desde hace más de seis años en la porción sur del valle, espacio en el que detectamos una particular concentración de los paneles en áreas acotadas del paisaje, situación que no se registra en otras áreas del oeste cordobés. En esta microrregión documentamos 37 paneles con representaciones rupestres pintadas y grabadas, distribuidas en 34 sitios situados puntualmente en la vertiente oriental de las Sierras de Pocho, en una extensión total que no supera los $15 \mathrm{~km}^{2}{ }^{1}$

Toda la región está conformada por rocas metamórficas y presenta numerosos afloramientos de tonalita, explotada comercialmente en la actualidad y conocida con la denominación de granito "gris mara". Los agentes naturales han erosionado estas formaciones rocosas dando lugar a bloques redondeados denominados tafones. Estas características geomórficas generan numerosos soportes potenciales para la ejecución de paneles con representaciones rupestres, sin embargo detectamos una clara selección en cuanto al tipo de sitio y las condiciones de visibilidad de los motivos ejecutados.

Dada la cantidad de lugares en los que registramos esta evidencia material y a fin de evitar una extensa descripción de cada uno de los paneles, agrupamos la evidencia en áreas definidas en función de la cercanía espacial, el emplazamiento en ambientes topográficos similares y/o por estar ubicados estos lugares en espacios que son reconocidos a partir de la toponimia cartográfica (fig. 1). Las áreas que se analizan en esta oportunidad son La Pampita, Cerco de la Cueva, Yaco Pampa, Cerco Otto, Barranca Honda y Charquina. En todas estas áreas se ha computado un total de 650 motivos identificados como zoomorfos, antropomorfos, fitomorfos, geométricos e indefinidos.

El área La Pampita está ubicada aproximadamente a $12 \mathrm{~km}$ al noroeste de la localidad de La Playa. Es uno de los sectores de mayor altitud de la microrregión de Guasapampa (800 msnm), característica que justifica su denominación aunque las especies típicas del bosque chaqueño no pierden su preponderancia. Otra particularidad es que no registra cursos de agua estacionales. Distribuidos en tres sitios documentamos tres paneles con un total de 29 representaciones rupestres pintadas en blanco, negro y rojo, distribuidas en tres sitios.

El área de Cerco de la Cueva está emplazada en la margen izquierda del río Guasapampa y distante $2 \mathrm{~km}$ aproximadamente de la localidad de La Playa. En el ámbito de la microrregión es la que presenta un entorno cultural y ambiental más afectado, dado que ha sido objeto de una sobreexplotación de los bancos de granito. En esta área se documentaron seis sitios, entre los que se distribuyen siete paneles con 143 motivos entre pintados, en blanco, negro, rojo y amarillo, y grabados $(n=2){ }^{2}$ 
Yaco Pampa se encuentra a $5 \mathrm{~km}$ en línea recta de la localidad de La Playa. Todo el sector está asociado a una vertiente de agua, que desaparece sólo en épocas de grandes sequías, que discurre por una quebrada de reducidas dimensiones. Está conformada por dos sitios con dos paneles donde contabilizamos 25 motivos pintados en blanco. Asimismo, documentamos la única ocupación al aire libre registrada hasta el momento en la microrregión.

Emplazado a $5 \mathrm{~km}$ al oeste de la localidad de La Playa está ubicada el área denominada Cerco Otto, caracterizada por un paisaje irregular y dominado por el Chaco Serrano. No observamos cursos de agua de carácter estacional dentro de los límites del Cerco. En Cerco Otto se documentaron tres sitios con tres paneles con 72 representaciones rupestres pintadas en negro y blanco, así como motivos grabados $(n=1)$.

El área de Barranca Honda se encuentra a $3,5 \mathrm{~km}$ de la localidad de La Playa y está surcada, en dirección oeste-este, por el arroyo Barranca Honda que tiene un marcado carácter estacional. Este curso de agua serrano es el único de esta zona que desemboca en el río Guasapampa, dado que los otros se pierden en el manto sedimentario. Está caracterizada por un relieve accidentado y entre los soportes potenciales que la conforman documentamos un total de cinco sitios o lugares, que presentan en sus paredes rocosas cinco paneles. Entre estos se distribuyen 91 motivos pintados en blanco y negro.

Finalmente, a $10 \mathrm{~km}$ en dirección sudoeste de la localidad de La Playa está ubicada el área de Charquina. De paisaje muy accidentado, registra la altura máxima de la microrregión de Guasapampa con el cerro Orcosuni que cuenta con 870 msnm. Está surcada por algunos arroyos de marcado carácter estacional, que superada la época estival constituyen verdaderos senderos arenosos que cortan la cerrada vegetación chaqueña. Aquí documentamos la mayor cantidad de sitios con representaciones rupestres, que suman un total de 15 . Entre estos están distribuidos 17 paneles con un total de 290 motivos pintados en blanco, negro y rojo, y algunos grabados $(n=6)$.

\section{Principales características del arte rupestre de Guasapampa}

Como mencionamos anteriormente, para el estudio del arte rupestre consideramos algunas variables de análisis que nos permiten acceder tanto a los rasgos estandarizados como a aquellos que denotan una especificidad y particularidad en el universo total de la muestra. Así, para el estudio comparativo entre las áreas tomaremos tipos de motivos, diseños o patrones constructivos, asociaciones temáticas y, finalmente, las condiciones de visibilidad involucradas en la selección de los soportes.

\section{Motivos identificados en los paneles}

Entre los motivos documentados en la sección sur del valle de Guasapampa se identificaron zoomorfos, antropomorfos, fitomorfos, geométricos e indefinidos, que están ejecutados mayoritariamente con pintura blanca, negra, roja y amarilla y en una baja proporción mediante el grabado. Los datos cuantitativos permiten observar el marcado predominio de las representaciones de animales, dado que conforman el $72 \%(n=450)$ del total, por sobre los demás tipos identificados. Asimismo, dentro de este grupo sobresale por un lado el alto número de camélidos y, por otro, la amplia distribución de esta figura entre la mayoría de las áreas (Tabla 1).

Sin embargo, en el marco de un análisis más abarcativo, documentamos otros motivos que marcan una clara especificidad dado que conforman figuras únicas o escasamente distribuidas, es decir, que se restringen a puntos particulares del paisaje. Los casos que dan cuenta de esta situación son el felino y el pecarí dentro del grupo de los zoomorfos y el ucle (Cereus validus), que constituye el único en su tipo, que están presentes sólo en cuatro de los paneles que se integran a las áreas de Cerco Otto, Yaco Pampa y Charquina.

El felino está ejecutado mediante el grabado de la superficie, pero no de cuerpo lleno; su definición morfológica está constituida por la unión de numerosos círculos picados en la superficie de la roca (fig. 2). Son estos círculos los que podrían hacer referencia a las manchas u ocelos negros que cubren el cuerpo de algunas especies de felinos que habitan o habitaban el área, como el yaguareté también denominado "tigre" (Pantera onca), hoy extinto en la región, o el gato montés (Oncifelis geoffroyi). Asimismo, en las cuatro extremidades están destacados los dedos de las patas y manos del animal. El otro motivo identificado corresponde a un pecarí de collar (Pecari tajacu) ejecutado en blanco, especie propia de los ambientes chaqueños, y se define en base a la comparación con su referente real. En este sentido, el detalle de su cuerpo robusto, patas cortas, sus orejas pequeñas y su cola apenas distinguible conforman los rasgos que respaldan esta asignación, dado que constituyen las particularidades morfológicas del animal (fig. 3). En tanto los dos motivos fitomorfos, documentados en las áreas de Charquina y Yaco Pampa, hacen referencia a los ucles o cardones, especie de la familia de las cactáceas, ampliamente documentadas en los ambientes del Chaco Serrano (fig. 4). 
Tabla 1. Distribución de los tipos de motivos entre las áreas de Guasapampa Sur Table 1. Distribution of motif type in Guasapampa Sur, by area

\begin{tabular}{|c|c|c|c|c|c|c|c|c|c|c|c|c|}
\hline & \multicolumn{2}{|c|}{ La Pampita } & \multicolumn{2}{|c|}{$\begin{array}{l}\text { Cerco de } \\
\text { la Cueva }\end{array}$} & \multicolumn{2}{|c|}{ Yaco Pampa } & \multicolumn{2}{|c|}{ Cerco Otto } & \multicolumn{2}{|c|}{$\begin{array}{c}\text { Barranca } \\
\text { Honda }\end{array}$} & \multicolumn{2}{|c|}{ Charquina } \\
\hline & $\mathrm{n}$ & $\%$ & $\mathrm{n}$ & $\%$ & $\mathrm{n}$ & $\%$ & $\mathrm{n}$ & $\%$ & $\mathrm{n}$ & $\%$ & $\mathrm{n}$ & $\%$ \\
\hline Camélido & 8 & 28 & 77 & 54 & 16 & 67 & 44 & 68 & 70 & 77 & 191 & 65 \\
\hline Cérvido & - & - & - & - & 1 & 4 & 2 & 3 & 4 & 4 & 2 & 1 \\
\hline Cánido & - & - & 2 & 1 & - & - & 1 & 2 & 1 & 1 & - & - \\
\hline Felino & - & - & - & - & - & - & 1 & 2 & - & - & - & - \\
\hline Rhea & - & - & 11 & 8 & - & - & 5 & 8 & - & - & 11 & 4 \\
\hline Reptil & - & - & - & - & - & - & - & - & 7 & 8 & - & - \\
\hline Pecarí & - & - & - & - & 1 & 4 & - & - & - & - & - & - \\
\hline Equino & - & - & - & - & - & - & - & - & - & - & 4 & 1 \\
\hline Antropomorfo & 1 & 3 & 6 & 4 & - & - & - & - & 1 & 1 & 3 & 1 \\
\hline Fitomorfo & - & - & - & - & 1 & 4 & - & - & - & - & 2 & 1 \\
\hline Circular & 1 & 3 & 6 & 4 & 2 & 8 & - & - & 4 & 4 & 14 & 5 \\
\hline Circular con apéndice & - & - & - & - & - & - & - & - & 2 & 2 & - & - \\
\hline Líneas & 13 & 45 & 21 & 15 & - & - & 6 & 9 & 2 & 2 & 24 & 8 \\
\hline Cuadrangulares & - & - & - & - & - & - & - & - & - & - & 5 & 2 \\
\hline Indefinidos & 6 & 21 & 20 & 14 & 4 & 8 & 3 & 5 & - & - & 34 & 12 \\
\hline
\end{tabular}

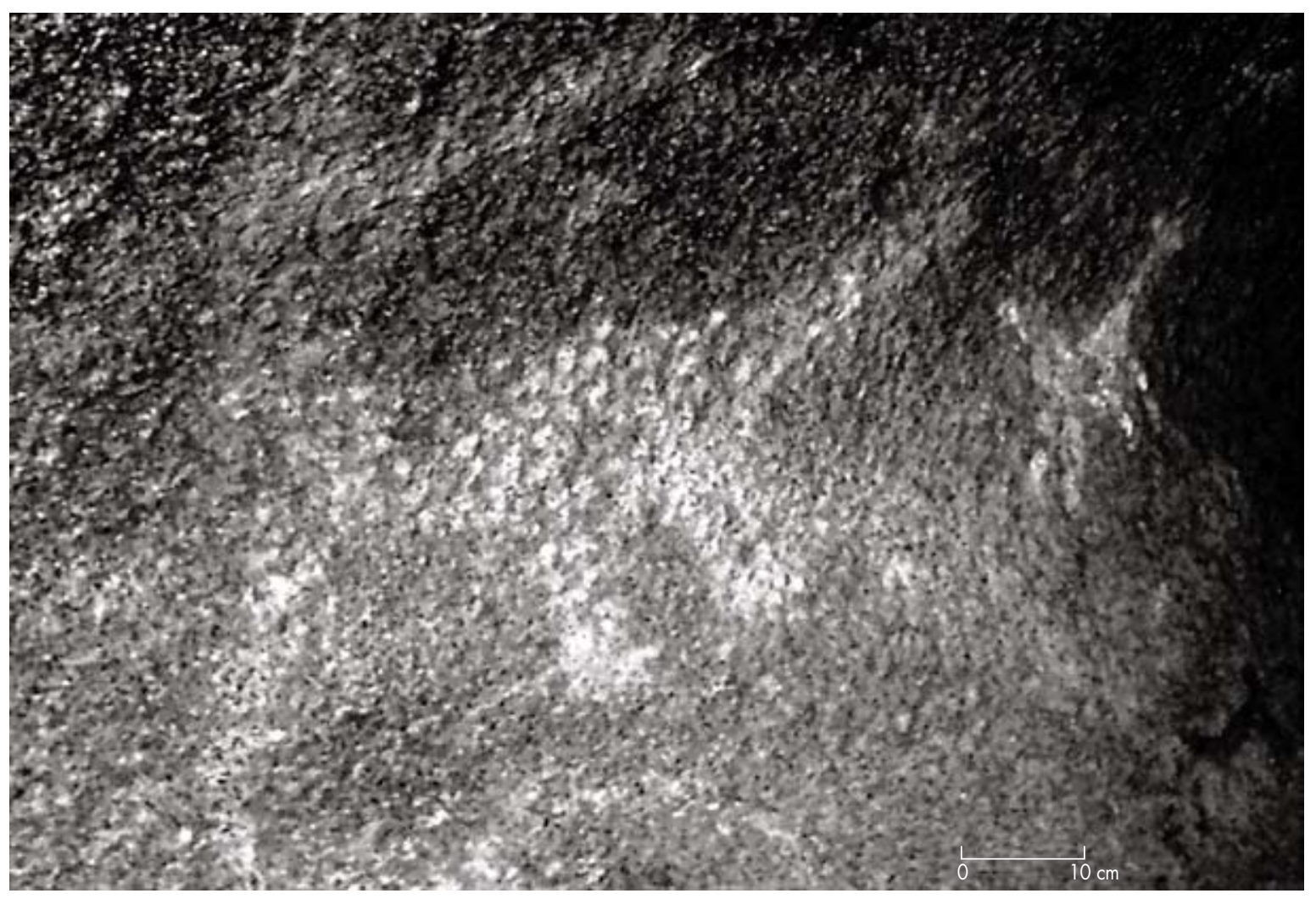

Figura 2. Detalle del felino registrado en el área de Cerco Otto.

Figure 2. Detail of feline registered in the Cerco Otto area. 
Estas son las únicas figuras que no circulan entre los grupos que ocupan el paisaje de Guasapampa, conformando así rasgos que caracterizan, individualizan y distinguen a los lugares en los que fueron ejecutados y, desde nuestra perspectiva de análisis, también a las personas que lo integran y los construyen cotidianamente. ${ }^{3}$

Entre los demás motivos clasificados como zoomorfos, son los reptiles los que muestran una mayor concentración en determinadas áreas, dado que sólo fueron ejecutados en los paneles de Charquina y de Barranca Honda. Están definidos, a partir de la comparación con el referente formal, como Tupinambis sp. (iguanas) que se encuentra profusamente en la microrregión de Guasapampa.

El resto de las representaciones identificadas como especies animales, por ejemplo los rheas, cánidos y cérvidos, y como antropomorfos y geométricos, muestra una frecuencia similar en las áreas presentes y se distribuye de manera relativamente equitativa entre las mismas, dando cuenta de motivos que circulan entre las áreas. La única excepción, tal como lo muestra la Tabla 1, es La Pampita, área en la cual el porcentaje total está dominado por motivos geométricos, fundamentalmente lineales.

Finalmente, los motivos clasificados como indefinidos reúnen a aquellos en los que no se puede establecer una comparación con un referente real. No obstante, el 73\% $(n=51)$ de las representaciones pueden ser identificados como motivos zoomorfos y, aunque lo deficiente de su conservación limite su adscripción, es factible señalar que podría tratarse de camélidos.

\section{Variaciones de diseños o cánones}

El estudio de los diseños parte de distinguir un modelo constructivo particular, en el cual juegan dimensiones diferentes y una determinada resolución de las formas (Aschero 1996). Por lo tanto, un mismo canon puede incluir distintos patrones o formas en las que se resuelve ese diseño. Entre los distintos tipos de motivos que se identificaron en la microrregión, describiremos de manera detallada sólo aquellos que permiten reconocer tanto rasgos estandarizados como únicos y que, en consecuencia, autorizan una mayor especificidad a los elementos que circulan en el paisaje. En función de ello, hemos efectuado un recorte sobre el total de la muestra que incluye los zoomorfos, fitomorfos y antropomorfos.

Así, se reconocieron variaciones entre los camélidos, los rheidae y los reptiles; en la resolución de las figuras humanas, por otra parte, se determinó e identificó un único diseño, con mínimas variantes en algunos de los paneles.

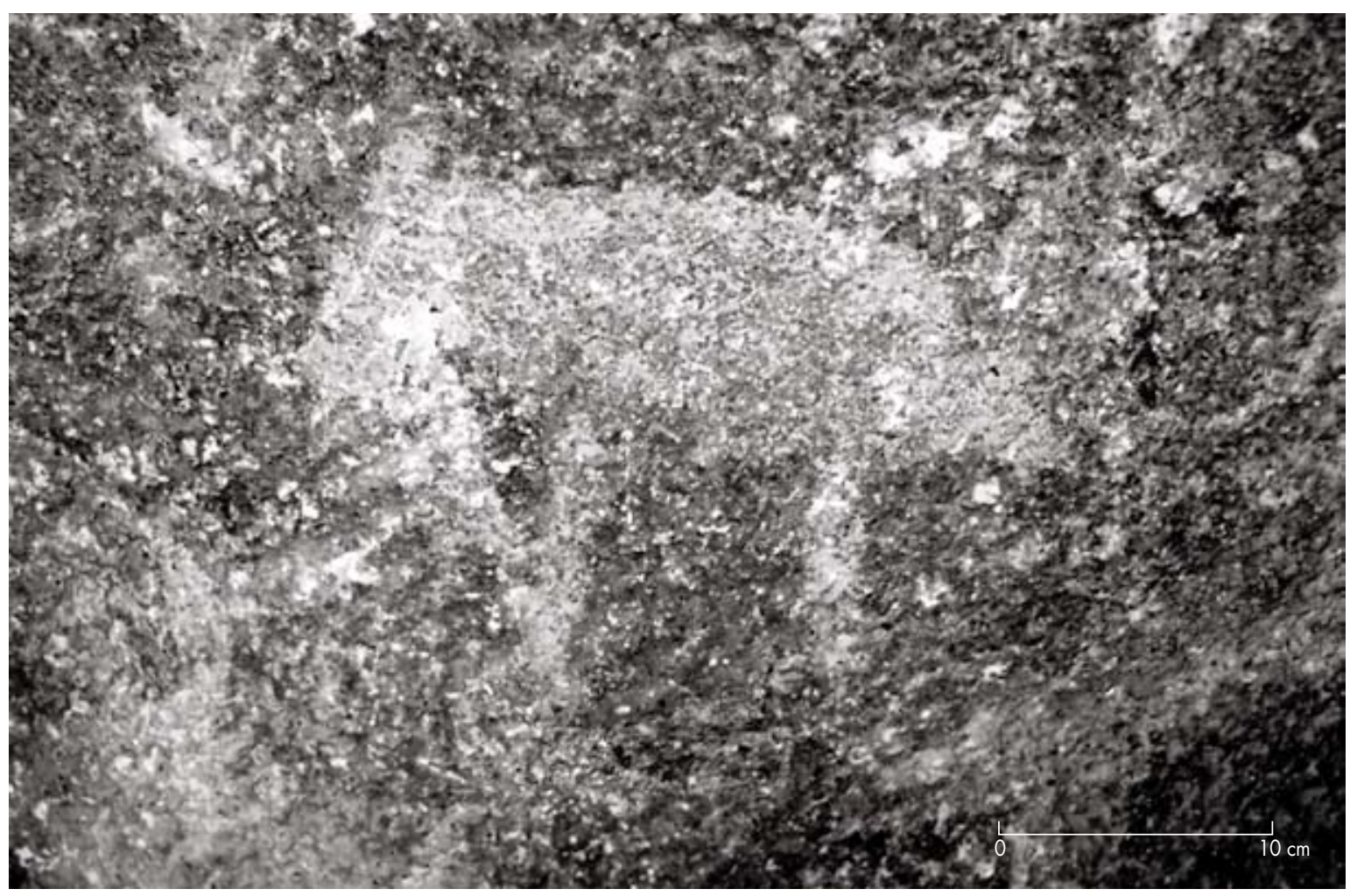

Figura 3. Área de Yaco Pampa, detalle del pecarí de collar (Pecari tajacu).

Figure 3. Detail of collared peccary (Pecari tajacu) in the Yaco Pampa area. 


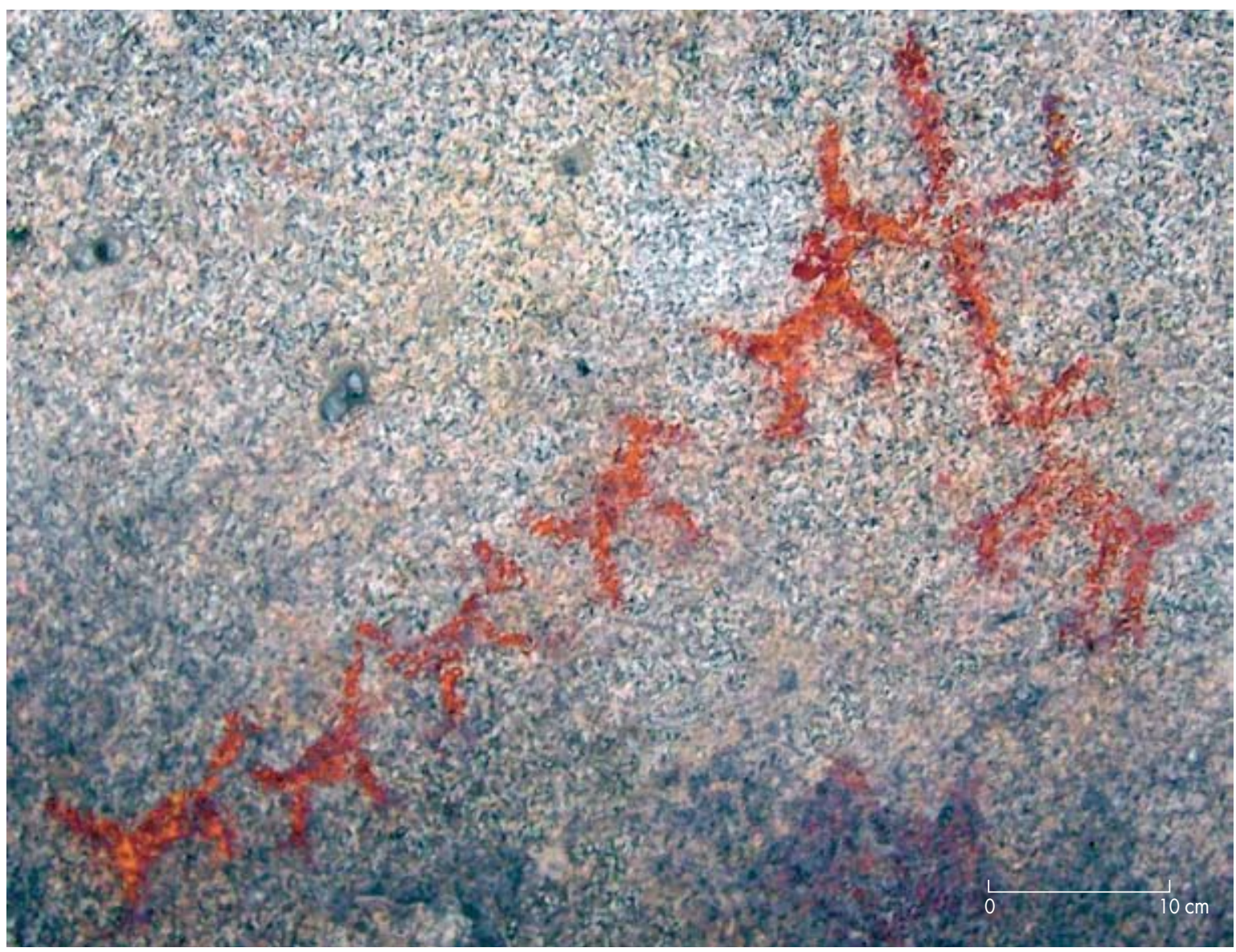

Figura 4. Panel de Charquina en el que se distingue la figura de un ucle (Cereus validus).

Figura 4. Charquina Panel with the distinct figure of a cactus (Cereus validus).

El análisis de los patrones constructivos de los camélidos en Guasapampa permitió distinguir cinco diseños o cánones diferentes, los que a su vez manifiestan algunos rasgos o patrones disímiles (fig. 5). El canon A, identificado en las seis áreas, se caracteriza por un esquema constructivo que parte de un cuerpo con forma elíptica, a la que se agregan el cuello y la cabeza, las extremidades y la cola. En este diseño se respetan, en general, las proporciones entre el cuerpo y las extremidades. El animal se muestra de perfil pero con la indicación en el mismo plano de las cuatro patas y las dos orejas. Asimismo, reconocemos algunos patrones o variaciones en el interior del canon, centrados fundamentalmente en la desproporción del cuello y el resto del cuerpo y en la condición estática de algunos diseños. Está asociado generalmente a otros camélidos y a motivos geométricos. En las áreas Cerco de la Cueva, Charquina y La Pampita documentamos una variación de este canon, que se distingue por mostrar una definición más cuadrada de todas las partes constitutivas del animal y está asociado a motivos geométricos, antropomorfos y zoomorfos (camélidos).

El canon B, distribuido en Cerco de la Cueva, Charquina, Barranca Honda y La Pampita, parte de un esquema constructivo diferente del anterior ya que se remarcan los cuerpos alargados y amorfos, sin respetar las proporciones del referente objetivo. Las patas están bien diferenciadas y separadas, aunque no guardan relación con el cuerpo y se insertan en el pecho de animal. En los paneles se encuentra asociado generalmente con otros camélidos.

El canon C, localizado solamente en Cerco de la Cueva, Charquina y Barranca Honda, se caracteriza por un diseño que se define por un cuerpo de trazo más cuadrangular que los anteriores, donde se insertan las patas y el cuello, en una directa relación con el referente formal. En el trazado destaca la inserción y la disposición del cuello, como el pecho del animal. La figura combina dos planos, ya que el cuerpo y las patas están de perfil (se indican dos patas), pero la cabeza está de tres cuartos 


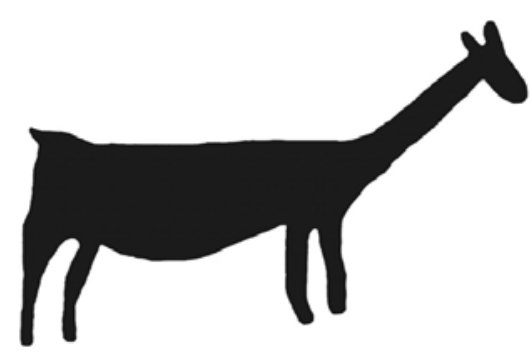

Canon A

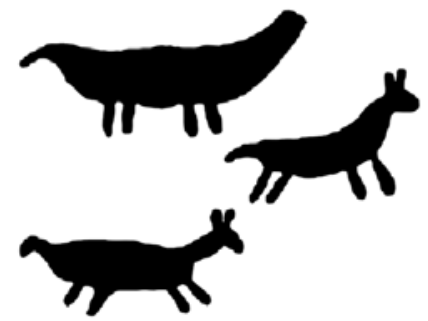

Canon B

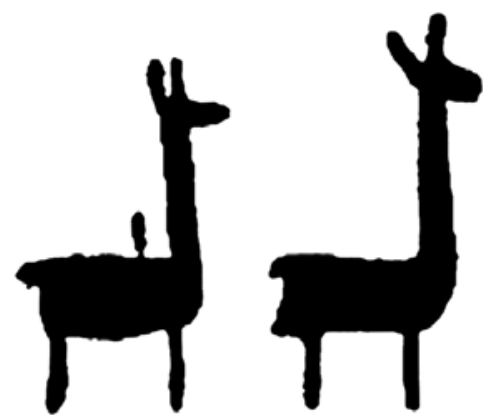

Canon C
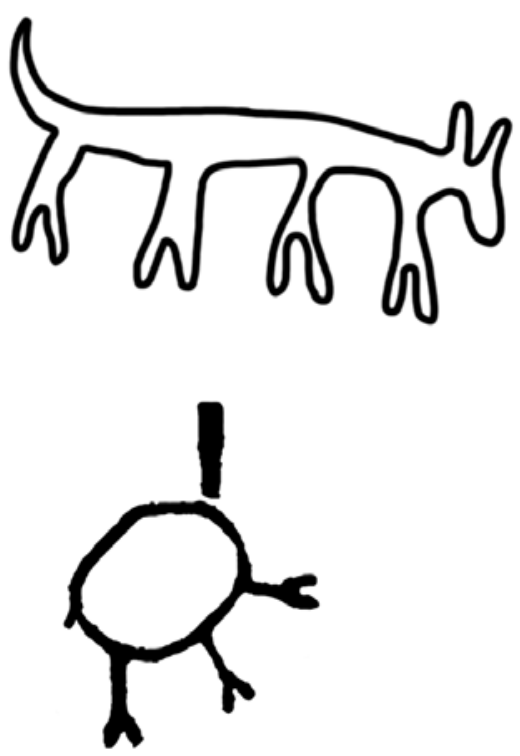

Canon D

Canon $\mathrm{E}$

Figura 5. Detalle de los cinco cánones identificados en las distintas áreas

Figure 5. Detail of the five canons identified in the different areas. perfil ya que están indicadas las dos orejas. En un sitio de Charquina este es el único canon que registra la técnica del grabado en su ejecución. Este motivo está asociado con representaciones antropomorfas, zoomorfas (ñandú y ciervos), como con motivos geométricos.

En tanto el canon D, con excepción de Cerco de la Cueva, fue registrado en las restantes cinco áreas. Su diseño no respeta las proporciones del referente real y se caracteriza porque su trazado es simple y lineal, en el cual cola, cuerpo, cuello y cabeza conforman un todo. Están presentes las cuatro extremidades, aunque distribuidas de manera aleatoria, y las dos orejas, lo que indica que sólo el cuerpo del camélido está de perfil. Asimismo, por la disposición de sus patas, en general, tienen una postura estática. Está asociado específicamente a otros motivos zoomorfos (camélidos).

Finalmente, el canon E sólo se distribuye entre las áreas de Cerco de la Cueva y La Pampita. Consiste en una resolución muy esquemática de la figura, conformada por un círculo al cual se agregan las extremidades y el cuello. En un motivo están indicadas las cuatro patas y en otro sólo destacan tres, pero todas tienen el detalle de la pezuña del animal. El motivo está ejecutado en negro y, dado el mal estado de conservación, carece de cabeza. Esta figura se vincula temáticamente a una representación geométrica y a otros camélidos.

Entre los motivos que prácticamente no dan cuenta de variaciones en sus resoluciones formales trataremos las representaciones identificadas como aves caminadoras (ñandú) y reptiles (iguana). Ambas muestran características semejantes, ya que se observa un único diseño, cuyas variantes están vinculadas con la simplificación de esos cánones constructivos originales. El patrón de resolución de las rheas registradas en Guasapampa parte de una definición redondeada o elíptica del cuerpo, al cual se agregan un cuello largo, dos alas y dos extremidades inferiores que pueden o no culminar en las garras tridígitas del ave (fig. 6a). El segundo es diferente, dado que el ave representada es apenas una resolución esquemática del referente formal (fig. 6b). Este diseño se registró únicamente en un panel dentro del área de Charquina.

En el caso de las iguanas, se identificaron dos patrones constructivos. En el primero se respetan las proporciones y los rasgos constitutivos, es decir, una cabeza triangular, las cuatro extremidades cortas y extendidas, que pueden o no tener la indicación de los dedos, y la larga cola que se afina paulatinamente (fig. 7a). El segundo patrón, que entendemos como una simplificación del primero, se diferencia principalmente por una cabeza redonda y un cuerpo definido en base a líneas rectas que conforman el cuerpo y las extremidades (fig. 7b). 

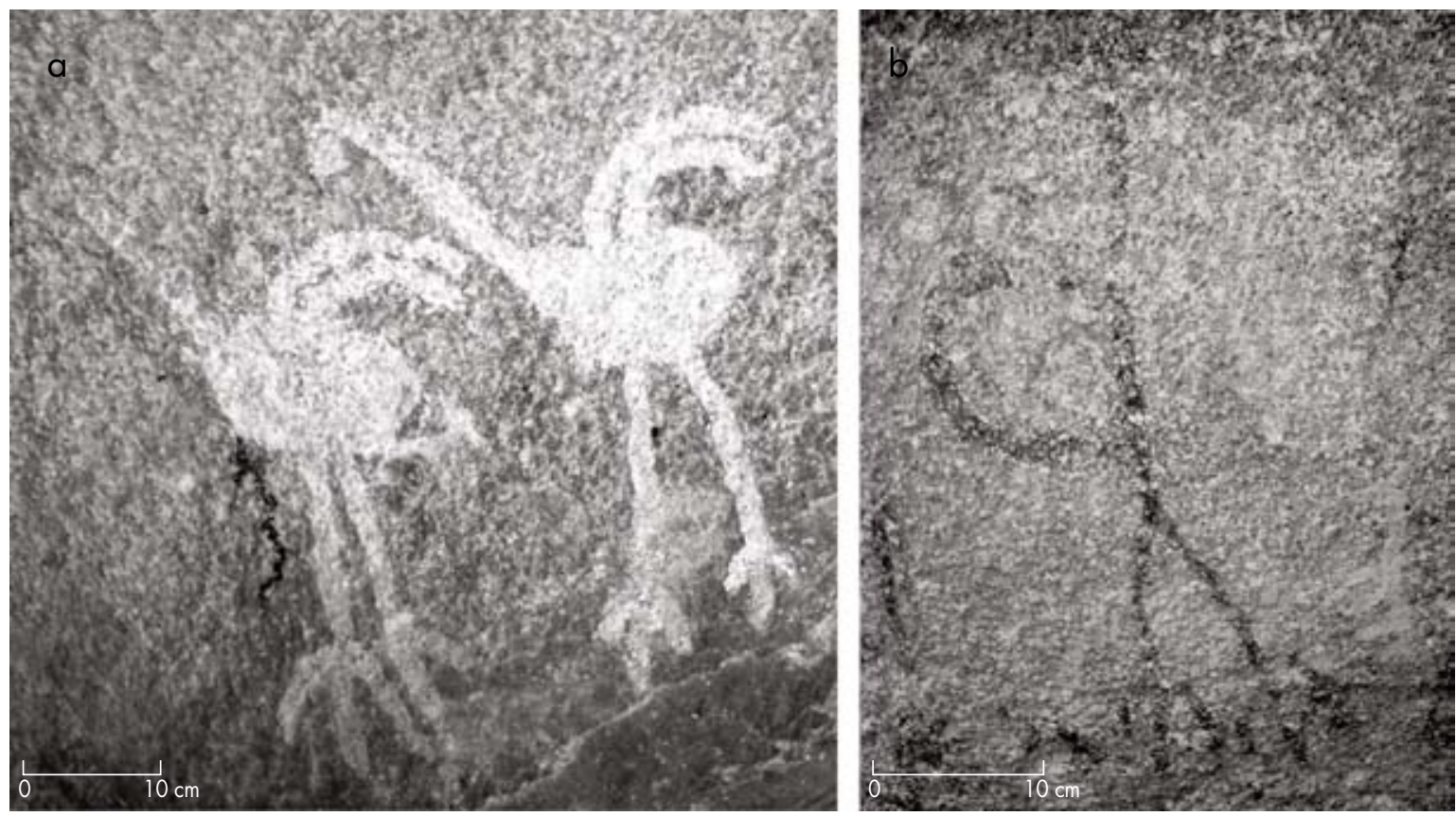

Figura 6. Comparación de los patrones de diseño de ñandúes (Rheas sp.) identificados en Cerco Otto (izquierda) y Charquina (derecha). Figure 6. Comparison of ñandú (Rheas sp.) design patterns identified at Cerco Otto (left) and Charquina (right).
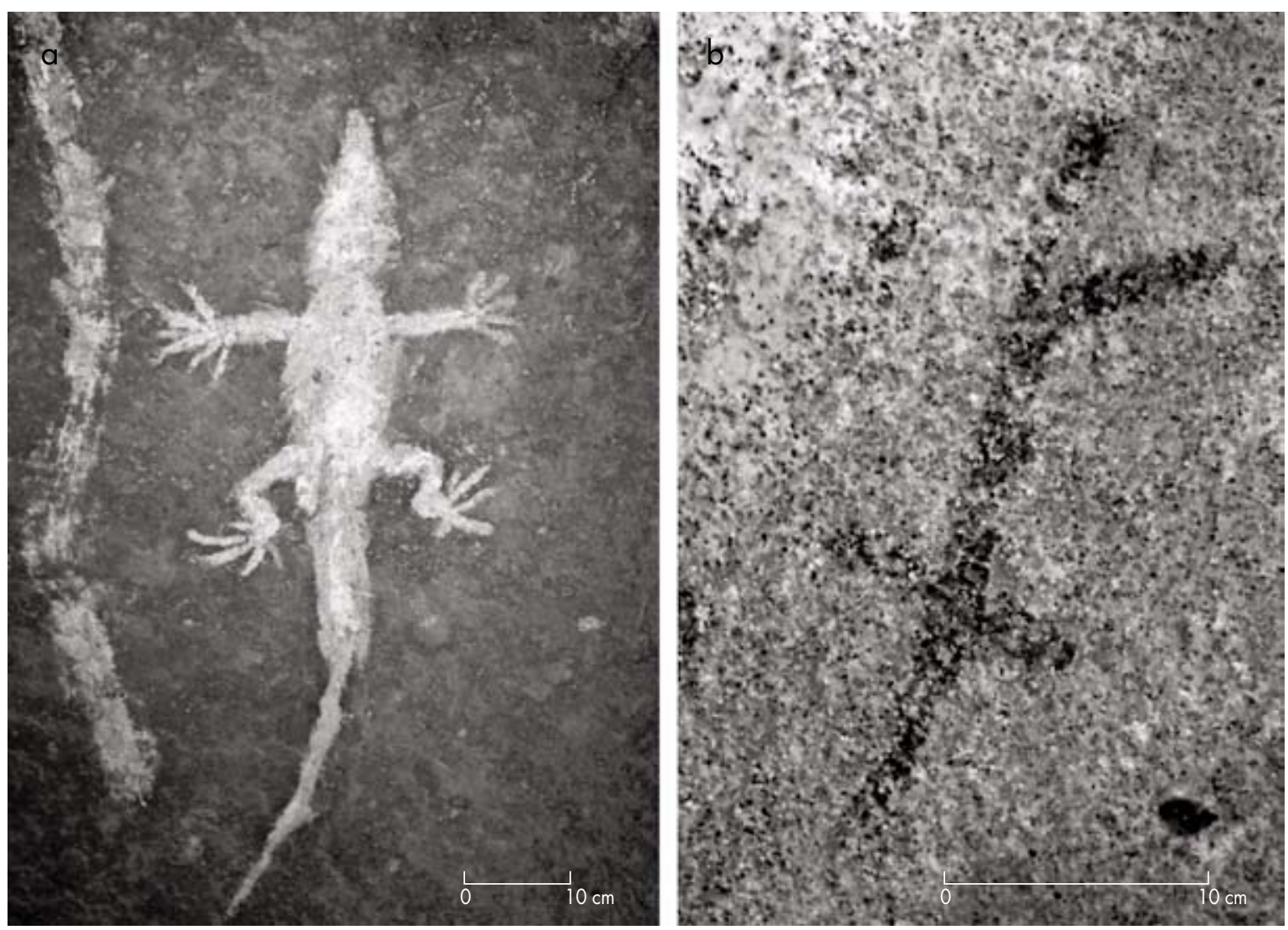

Figura 7. Detalle de las iguanas (Tupinambis sp.) registradas en Guasapampa Sur. Figure 7. Detail of iguanas (Tupinambis sp.) registered at Guasapampa Sur. 
La definición de la figura humana es el ejemplo más concreto de la presencia de un único diseño que circula entre los paneles emplazados en las áreas (figs. $8 \mathrm{a}$ y 8b) y entre los cuales consideramos que las diferencias están denotando distintas "manos" ejecutando lo mismo. En este sentido, el motivo identificado en La Pampita (fig. 8b) presenta un detalle ubicado, posiblemente, en

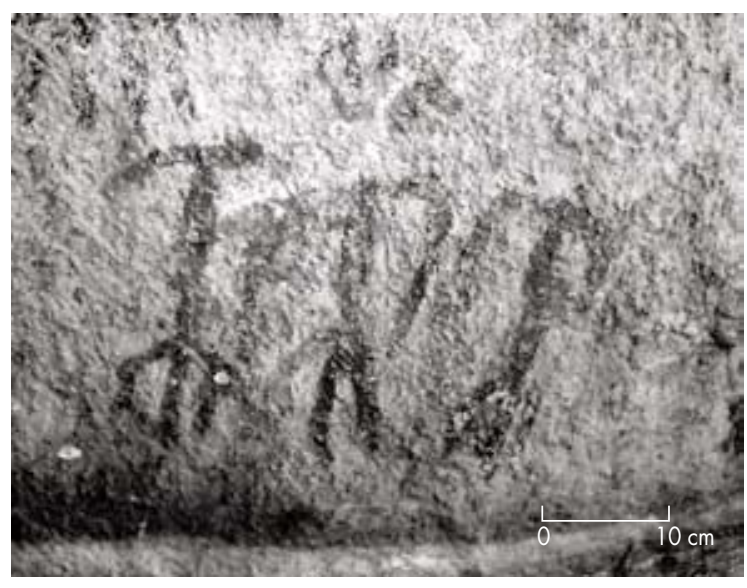

Figura 8a. Detalle del motivo antropomorfo identificado en el área de Cerco de la Cueva.

Figure 8a. Anthropomorphic detail identified in Cerco de la Cueva area.

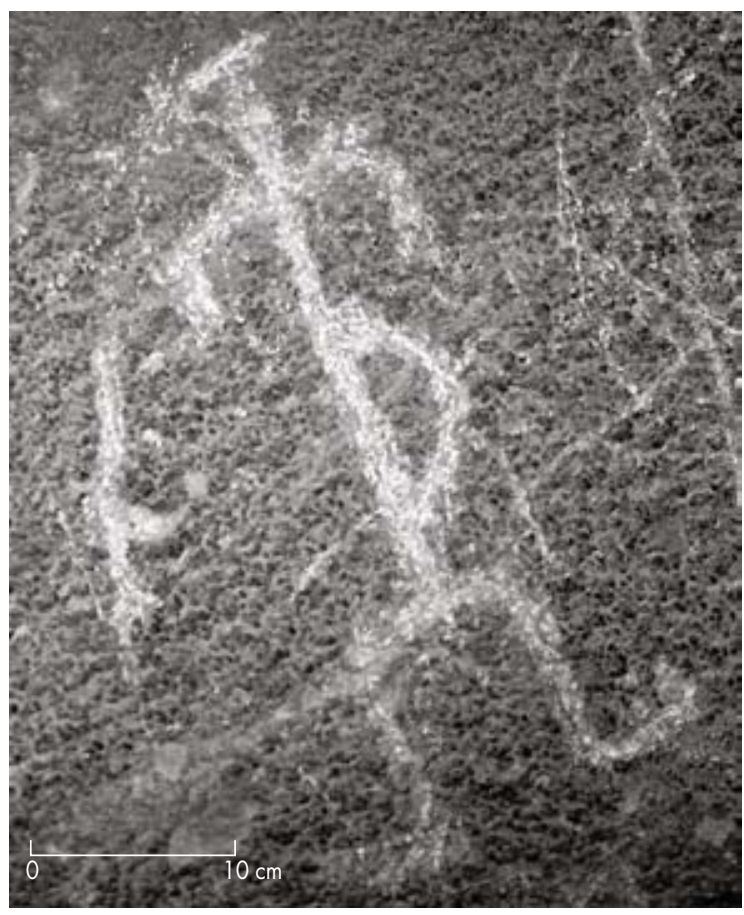

Figura 8b. Motivo antropomorfo identificado en el área de La Pampita.

Figure 8b. Anthropomorphic motif identified in La Pampita area. la espalda. Dadas las características del mismo, podría tratarse de algún adorno o detalle dorsal. No obstante, el diseño común a todos los antropomorfos se caracteriza por trazados lineales del total de la figura, en la cual los brazos apenas destacan y, en la mayoría de los casos, se despliegan conformando una "T" o una "M" con el torso. En gran parte de los motivos no está indicada la cabeza ni el cuello, y sólo aparece como una prolongación del tronco o como un pequeño trazo perpendicular respecto al cuerpo. Además, en el área de Cerco de la Cueva, los antropomorfos presentan la indicación del sexo, en algunos casos se presenta muy destacado respecto a las proporciones del cuerpo.

Finalmente, los motivos geométricos presentan características semejantes respecto a los camélidos, dado que por un lado se distribuyen entre todas las áreas (véase Tabla 1) y, por otro, no registra variaciones significativas respecto al diseño de los motivos. En cuanto a este último punto, las únicas excepciones son los motivos documentados en Barranca Honda y Charquina (circular con apéndice y cuadrangulares respectivamente), que lejos de mostrar una amplia distribución constituyen tipos de motivos cuya ejecución está vinculada sólo a esas áreas y, en su interior, a puntos acotados en el paisaje.

\section{Asociaciones de motivos o temas}

Otra variable significativa para marcar semejanzas y diferencias es el análisis de las asociaciones temáticas, esto es, el estudio de la manera en que los motivos se vinculan en los paneles. El tema involucra tanto asociaciones de motivos que admiten cierta sincronía en su ejecución como representaciones agregadas a temas preexistentes (Aschero 1994), dado tanto por proximidad espacial como por superposiciones. Incluso se pueden determinar temas entre asociaciones de motivos con diferente resolución estilística, ya que lo importante es la significación que se vincula a lo temático.

La comparación efectuada entre las áreas nos permite advertir que, a pesar de que los camélidos constituyen el rasgo constante y el elemento estructurante de una gran cantidad de temas (incluso llegan a conformar escenas en sí mismos), las diferencias se perciben con relación a los otros motivos involucrados en la conformación de estas asociaciones (Tabla 2). Los artiodáctilos se asocian con antropomorfos, reptiles, rheas e incluso felinos, equinos y geométricos, registrándose más de una escena en un mismo sitio. Son estas figuras vinculadas al camélido las que marcan especificidades y que rompen con la aparente estandarización que tiene a este animal como eje. De la misma manera, hay asociaciones que 
Tabla 2. Distribución de las asociaciones de motivos identificadas en las distintas áreas Table 2. Distribution of motif associations identified, by area

\begin{tabular}{|c|c|c|c|c|c|c|c|c|c|c|c|c|c|c|}
\hline & \multicolumn{2}{|c|}{ La Pampita } & \multicolumn{2}{|c|}{$\begin{array}{l}\text { Cerco de } \\
\text { la Cueva }\end{array}$} & \multicolumn{2}{|c|}{ Yaco Pampa } & \multicolumn{2}{|c|}{ Cerco Otto } & \multicolumn{2}{|c|}{$\begin{array}{l}\text { Barranca } \\
\text { Honda }\end{array}$} & \multicolumn{2}{|c|}{ Charquina } & \multicolumn{2}{|c|}{ TOTAL } \\
\hline & $\mathrm{n}$ & $\%$ & $\mathrm{n}$ & $\%$ & $\mathrm{n}$ & $\%$ & $\mathrm{n}$ & $\%$ & $\mathrm{n}$ & $\%$ & $\mathrm{n}$ & $\%$ & $\mathrm{n}$ & $\%$ \\
\hline Asociación de camélidos & 1 & 25 & 4 & 21 & 1 & 20 & 2 & & 2 & 25 & 7 & 20 & 17 & 22 \\
\hline Camélido aislado & - & - & - & - & - & - & 1 & & - & - & 1 & 3 & 2 & 3 \\
\hline Camélido y felino & - & - & - & - & - & - & - & & 1 & 12,5 & - & - & 1 & 1 \\
\hline Camélidos y rheas & - & - & - & - & - & - & - & & - & - & 1 & 3 & 1 & 1 \\
\hline Camélidos, rheas y reptiles & - & - & - & - & - & - & 1 & & - & - & 6 & 17 & 7 & 9 \\
\hline Camélidos, rheas y geométricos & - & - & 1 & 5 & - & - & - & - & - & - & 3 & 9 & 4 & 5 \\
\hline Camélidos y cérvidos & - & - & - & - & - & - & - & - & - & - & - & - & 1 & 1 \\
\hline Camélido, cérvido y geométrico & - & - & - & - & 1 & 20 & - & - & - & - & - & - & 1 & 1 \\
\hline Camélidos, cérvidos y rhea & - & - & - & - & - & - & - & - & 1 & 12,5 & - & - & 1 & 1 \\
\hline Camélido, rhea y cánido & - & - & 1 & 5 & - & - & - & - & - & - & - & - & 1 & 1 \\
\hline Camélidos y cánidos & - & - & 2 & 11 & - & - & - & - & 1 & 12,5 & 1 & 1 & 4 & 5 \\
\hline Camélidos y reptiles & - & - & - & - & - & - & - & & - & - & 1 & 1 & 1 & 1 \\
\hline Camélidos y fitomorfos & - & - & - & - & - & - & 1 & & - & - & - & - & 1 & 1 \\
\hline Camélidos y geométricos* & 1 & 25 & 4 & 32 & 1 & 20 & 1 & & 1 & 12,5 & 6 & 17 & 14 & 18 \\
\hline Cérvidos, camélido y cánido & - & - & - & - & - & - & - & - & - & - & 1 & 1 & 1 & 1 \\
\hline Cérvido, camélido y geométrico & - & - & - & - & - & - & 1 & & - & - & - & - & 1 & 1 \\
\hline Rheas & - & - & - & - & - & - & 1 & & 2 & 25 & - & - & 3 & 4 \\
\hline Pecarí y zoomorfo (¿camélido?) & - & - & - & - & 1 & 20 & - & - & - & - & - & - & 1 & 1 \\
\hline Equinos & - & - & - & - & - & - & - & - & - & - & 2 & 3 & 2 & 3 \\
\hline Reptiles, líneas y equinos & - & - & - & - & - & - & - & - & - & - & 1 & 1 & 1 & 1 \\
\hline Fitomorfo & - & - & - & - & 1 & 20 & - & - & - & - & - & - & 1 & 1 \\
\hline Antropomorfo & - & - & 1 & 5 & - & - & - & - & - & - & - & - & 1 & 1 \\
\hline Antropomorfo y camélido (?) & - & - & 1 & 5 & - & - & - & - & - & - & 1 & 1 & 2 & 3 \\
\hline Antropomorfo, geométrico y camélido & - & - & 1 & 5 & - & - & - & - & - & - & 2 & 3 & 3 & 4 \\
\hline Antropomorfo y camélidos & 1 & 25 & - & - & - & - & - & - & - & - & 1 & 1 & 1 & 1 \\
\hline Geométricos & 1 & 25 & 2 & 11 & - & - & 1 & & - & - & 1 & 1 & 5 & 6 \\
\hline
\end{tabular}

* incluidos en este grupo están líneas, círculos y cuadrangulares.

circulan en el paisaje (camélidos/geométricos), en tanto que hay otras que presentan un registro más acotado (p. e., camélido, rhea y cánido).

Por otra parte, los diferentes tipos de diseño identificados, fundamentalmente entre los camélidos, no dan cuenta de una asociación particular con determinados motivos. Es decir, los cánones se vinculan de manera indistinta conformando temas diversos, e incluso se observa la presencia de más de un tipo de resolución en un mismo tema.

Asimismo, estos temas presentan condiciones de conformación específica con relación a la manera en la que se estructuran en el soporte. En este sentido, las diferencias tonales documentadas en algunos paneles nos han permitido proponer una cronología relativa para la ejecución de las distintas representaciones. Destacamos que los "nuevos" motivos o asociaciones se integran a los ya ejecutados o, por el contrario, son realizados en otros sectores del soporte dando lugar a nuevos y diferentes temas (fig. 9). En otros casos los motivos parecen realizados de manera aleatoria en el soporte, dando cuenta de una ejecución del tema de forma "desordenada" en el tiempo (fig. 10). Estos casos proporcionan los indicadores que nos autorizan a plantear que en los sitios cada uno de los temas se desarrolló con una cierta lógica interna que no niega lo previo, sino que se integra a él y lo complementa.

Hasta aquí las consideraciones respecto a la información recuperada del análisis de las variables vinculadas con los paneles, que podría tomarse como una mirada 
Tema 1

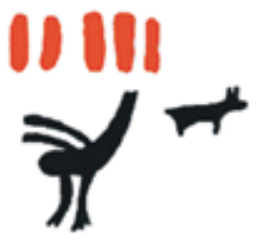

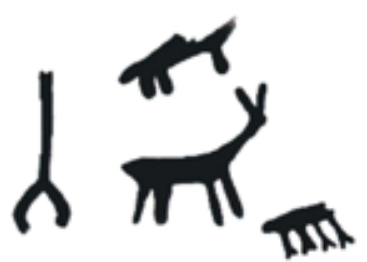

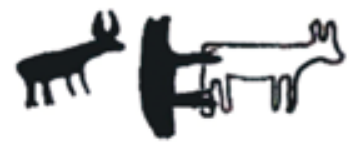

Tema 2

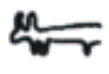

2

Figura 9. Panel del área de Charquina en el cual destaca la distribución de distintos temas en el soporte. Figure 9. Panel at Charquina area that highlights different themes in a single medium.

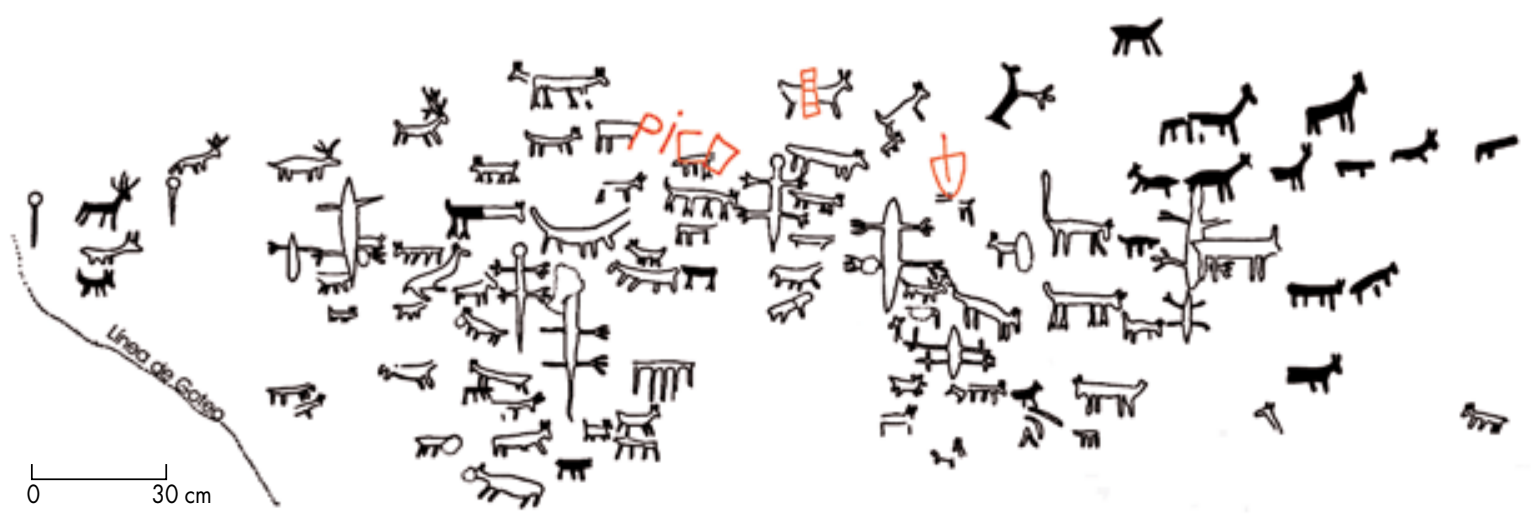

Figura 10. Panel del área de Barranca Honda en el cual se distingue la ejecución y distribución desordenada de los motivos. En rojo, daño moderno.

Figure 10. Panel from the Barranca Honda area with motifs executed and distributed in a disorganized manner. In red, recent damage to rock art site.

puntual y específica, pero que es necesario contextualizar a partir de un alejamiento que permita abarcar, en su totalidad, al soporte y al paisaje.

\section{Condiciones de visibilidad de paneles y soportes}

La ubicación del soporte y los paneles es resultado de una elección, por cuanto esta tiene una influencia directa en las condiciones de visibilidad de los mismos y por lo tanto en su interacción con el paisaje. Entendemos que en esta selección entra en juego la intencionalidad o no de hacer visible las acciones sociales (Criado Boado 1996).

En el valle de Guasapampa se han documentado tres tipos de soportes rocosos que fueron seleccionados para la ejecución de los motivos. Se trata de tafones, aleros o abrigos y salientes rocosas (fig. 11). Los primeros constituyen el 52\% $(n=19)$ del total de emplazamientos ponderados al momento de efectuar las representaciones pintadas o grabadas, seguidos en cantidad por los aleros rocosos que reúnen el $43 \%$ $(n=16)$ y finalmente las salientes con el $5 \%(n=2)$. Esta preponderancia relativa de los tafones permite marcar una tendencia en la que prevalece la invisibilidad de los paneles para las personas que circulan por el paisaje o, en otros términos, que tiene injerencia directa en el carácter restringido de la información transmitida y dirigida sólo hacia aquellos que ingresan, ocupan y construyen cotidianamente sus lugares. Además, esta situación se acrecienta si atendemos a las condiciones de emplazamiento de algunos de los aleros, ya que las particularidades de la formación en la que se ubican (p. e., un abrigo ubicado en medio de salientes rocosas 

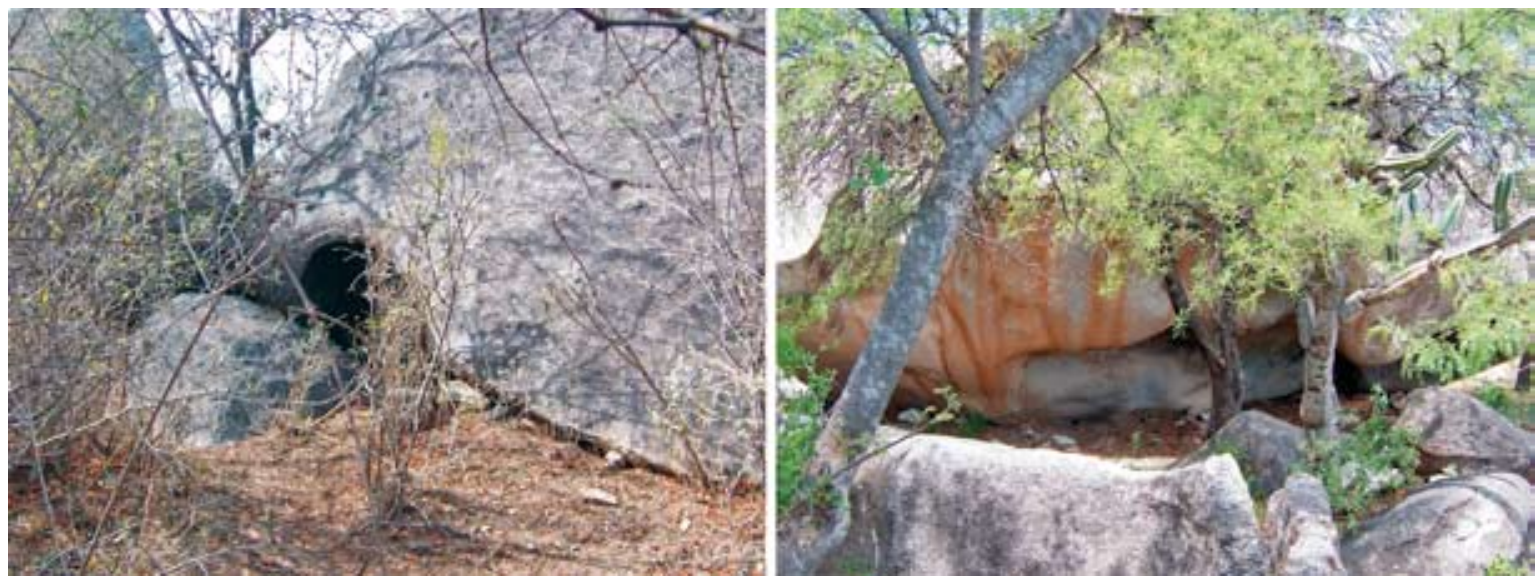

Figura 11. Tipos de soportes identificados en las áreas de Charquina (tafón de la izquierda) y Cerco Otto (alero rocoso de la derecha). Figure 11. Types of support media identified in the areas of Charquina ("taphon" boulder on the left) and Cerco Otto (rock overhang on the right).

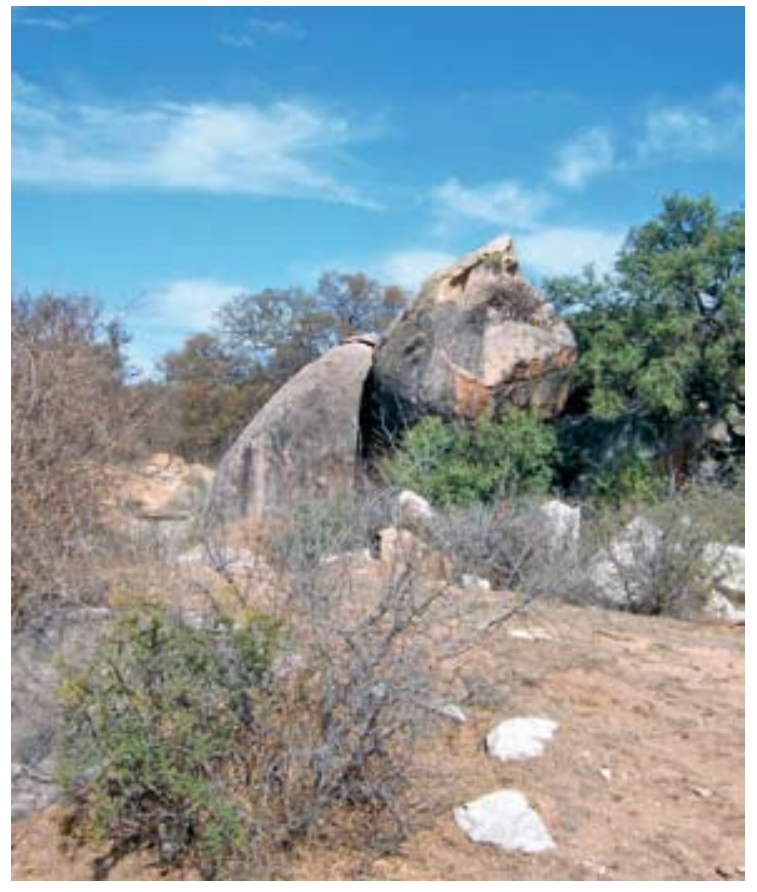

Figura 12. Tafón documentado en Charquina que da cuenta de su posición visible en el paisaje.

Figure 12. "Taphon" boulder documented at Charquina, showing its visibility in the landscape.

y las mínimas distancias requeridas para identificar los paneles) obstaculizaron o restringieron la observación de lo ejecutado. En este sentido, el 56\% ( $n=9)$ de los aleros presenta una visibilidad media y el 25\% ( $n=4)$, restringida respecto a lo ejecutado en sus paredes rocosas; la visibilidad alta o total de los paneles, en tanto, reúne sólo el 19\% ( $\mathrm{n}=3)$.
En la sección sur del valle de Guasapampa algunas de las formaciones rocosas elegidas para la construcción de los lugares constituyen rasgos destacados en el paisaje, ya sea por sus características morfológicas o sus dimensiones y, aunque conforman el 13,5\% $(\mathrm{n}=5)$ del total de la muestra, pudieron constituir puntos ordenadores del paisaje y de las conductas que en él se desarrollaron (fig. 12). Sin embargo, aun en estos casos, los paneles no son perceptibles dado que las figuras están ejecutadas en el interior, circunstancias que limitan la visualización.

\section{DISCUSIÓN DE LAS EVIDENCIAS}

La ocupación del valle de Guasapampa debe pensarse en tanto paisaje cuya evidencia da cuenta de un uso redundante del entorno. No obstante, éste no se relaciona con una utilización intensiva, dado que el patrón de dispersión de los sitios o lugares no es producto de la conformación de asentamientos multipropósitos al aire libre, o sea, poblados o caseríos tardíos que en otras zonas del valle de la región central de las Sierras Grandes se detectan en las márgenes de los colectores principales o en cursos tributarios asociados a terrenos potencialmente cultivables (Berberián et al. 2008). Asimismo, esta microrregión del oeste cordobés que no registra hasta ahora el desarrollo de una agricultura a pequeña escala, sí da cuenta de la explotación de recursos chaqueños.

Como ya mencionamos, se registraron 34 sitios con arte rupestre distribuidos en aleros y tafones entre los que se observan dos tipos de contextos. Algunos presentan evidencias de ocupación, determinadas por el hallazgo 
de rasgos superficiales o en estratigrafía, y otros en los cuales la ausencia de sedimento determina que el único dato concreto de uso está plasmado en las paredes rocosas. En la región de Guasapampa se practicaron intervenciones arqueológicas en cuatro puntos específicos del paisaje (Cerco de la Cueva 3, Charquina 2, Cerco de la Cueva Pintada y Yaco Pampa 1) donde se recuperaron cuatro fechados radiocarbónicos, que permitieron datar las ocupaciones en $390 \pm 60$ años AP (LP-1709), 1060 \pm 60 años AP (LP-1882) y $1190 \pm 90$ años AP (LP-2060) y $1360 \pm 60$ años AP (LP-1812; Recalde 2009).

La información estratigráfica recuperada está compuesta por artefactos líticos, cerámicos, restos arqueofaunísticos y arqueobotánicos. Estos datos nos han permitido proponer que en estos lugares se realizaron actividades domésticas, principalmente de mantenimiento y reparación de instrumentos, la ejecución de paneles con representaciones rupestres y el procesamiento y el consumo de especies silvestres, tanto animales como vegetales. La información arqueofaunística y arqueobotánica indica el consumo de recursos con una marcada estacionalidad como los huevos de Rheidae, que tienen una presencia significativa en el Número de especímenes identificados por taxón (NISP), y los fitolitos correspondientes a los frutos de chañar (Geoffroea decorticans) y algarrobo (Prosopis sp.) (Recalde 2008a, 2008b, 2009). De esta manera, los paneles se asocian a sitios monocomponentes, utilizados preponderantemente durante la época estival por un número reducido de personas, con fechados que oscilan entre $c a .1300$ y $360 \mathrm{AP}$, es decir, ocupaciones que abarcan toda la etapa que, en la cronología local, corresponde al Período Prehispánico Tardío. ${ }^{4}$

Específicamente proponemos que este entorno ambiental fue el punto de llegada de los grupos que se trasladaban, en época estival, desde sus poblados de origen. Aunque aún resta saber con exactitud desde dónde se trasladaban, las semejanzas ergológicas observadas en el registro material de Guasapampa con los hallados en el valle de Salsacate, distante aproximadamente $35 \mathrm{~km}$ en dirección sureste (Pastor 2007), permiten plantear que gran parte de los que construyeron y significaron el paisaje de la microrregión provenían de esta zona (Recalde 2009).

Además, la información analizada indica que en la región objeto de estudio los grupos construyeron un paisaje compartido en torno a la explotación de recursos extractivos propios de los ambientes chaqueños, fundamentalmente la recolección de frutos silvestres (Recalde 2009). Esta misma evidencia da cuenta también que esa ocupación del paisaje, que se prolongó por un período aproximado de mil años en función de los eventos datados en la microrregión, no registra modificaciones substanciales de los parámetros a partir de los cuales el paisaje fue significado y vivenciado como un constructo social. Este vínculo de los grupos con el entorno se reproduce en el tiempo, dejando "marcas" y rasgos que permiten comprenderlo como un paisaje histórico que se construye a partir de una doble estrategia de no exclusión entre los grupos, pero que a la vez refuerza la identidad de los que ocupan y utilizan cada uno de los sitios.

Sin embargo, esta propuesta nos ubica frente a una nueva problemática respecto a qué tipo de grupo estamos referenciando, dentro del proceso histórico regional, como los autores de los lugares documentados en Guasapampa sur. El estado actual de las investigaciones limita nuestra posibilidad de identificar en la cultura material distintos segmentos o unidades familiares e incluso linajes. En este sentido, sólo la información proporcionada por las fuentes documentales permite un acercamiento a la realidad social de las comunidades que ocupaban la región a mediados del siglo XVI. Los documentos han permitido reconstruir, parcialmente, las particularidades de la organización de los grupos serranos a la llegada de los españoles.

El paisaje social estaba organizado en torno a "pueblos", término que en los documentos hispánicos puede estar relacionado indistintamente con el espacio de asentamiento de un grupo determinado y, en un sentido más amplio y social, entendido como una congregación de individuos ligados por vínculos particulares (Bixio \& Berberián 1984; González Navarro 1999). Así, esta denominación tenía tanto una acepción política como territorial o geográfica. Estos pueblos estaban a su vez compuestos por un número variable de agrupaciones menores denominadas parcialidades (Piana de Cuestas 1992). Estas parcialidades llegaban a ocupar distintas áreas de una misma región, situación que no se traducía en un distanciamiento social, dado que los lazos de parentesco o amistad les permitían fortalecer el vínculo entre ellos y considerarse "todos uno" o, en otros términos, parte de un mismo "pueblo" (Bixio \& Berberián 1984). Estas relaciones eran reproducidas, fortalecidas y mantenidas a lo largo del tiempo a partir de la realización de actividades conjuntas (p. e., traslado a los algarrobales o uniones para la guerra o para las tareas agrícolas). ${ }^{5}$ Cada una de estas parcialidades estaba constituida por unidades familiares o domésticas, que han sido caracterizadas como familias extensas, aunque las fuentes pocos datos aportan para una definición más acabada (Bixio \& Berberián 1984).

En este contexto, proponemos que las personas que ocupan y construyen los sitios en Guasapampa 
conforman unidades domésticas, esto es, las células mínimas de agregación y, en este sentido, las similitudes documentadas en el arte rupestre de Guasapampa sur son el reflejo de la integración de estas unidades a una misma parcialidad, mientras las diferencias constituyen símbolos seleccionados por las personas que componen esa unidad familiar para fortalecer la cohesión interna. Reconocemos los riesgos que trae aparejado trasladar mil años la realidad social del siglo XVI, sin embargo, consideramos que los documentos nos permiten ser testigos del final de un proceso que, como tal, podemos rastrear en el tiempo. En este sentido, planteamos como hipótesis que puede generar líneas futuras de indagación, que el análisis del arte rupestre proporciona una vía para comenzar a darle base empírica a la conformación de la organización social de la cual dan cuenta los españoles, es decir, unidades domésticas integradas a distintos pueblos, que mantenían lazos de parentesco y unión.

Contamos con numerosas evidencias vinculadas a las particularidades de los motivos, los diseños y las asociaciones que respaldan la propuesta, respecto al papel activo que tienen las representaciones rupestres para quienes las ejecutan y las observan. Constituyen así estrategias tendientes a reproducir y apuntalar el sentido de pertenencia e identidad de las personas que integran estas unidades familiares de menor agregación y que ocupan los diferentes sitios o lugares de Guasapampa.

En primer lugar, el análisis de los motivos que están presentes en los distintos paneles permite inferir que hay una circulación diferencial de las figuras, fundamentalmente zoomorfas, antropomorfas y fitomorfas entre los lugares y, en consecuencia, entre las personas que construyen esos lugares a partir de la cotidianeidad de sus prácticas. Así, en el universo total de la muestra hay motivos que están presentes en la mayoría de los paneles (p. e., camélidos) y que dan cuenta de rasgos que son compartidos, reconocidos, reproducidos y significados de la misma manera por todas aquellas personas que ocupan el paisaje de la microrregión de Guasapampa. También hay otros que se difunden de forma más acotada (p. e., rhea), que podría estar dando cuenta de elementos que circulan sólo entre algunos lugares y que constituyen una información integrada a un código conocido sólo en el marco de un determinado conjuntos de personas; finalmente, existen representaciones que conforman elementos concretos, específicos e independientes, asociados sólo a determinados puntos del paisaje (felinos o ucles). Son estos últimos dos casos en los que nos detenemos al momento de reconocer lo único entre lo compartido, que aunque, como veremos más adelante, se integren a asociaciones de motivos comunes, su ejecución alude directamente a las particularidades de las personas que participan activamente en su observación, para las cuales ese motivo, en el marco de las asociaciones donde está presente, encierra una significación única a la unidad doméstica que interactúa con el panel en el ámbito de lo privado.

El análisis de los cánones o diseños constructivos y su distribución en el paisaje nos permite proponer que, en general, entre las seis áreas están circulando cánones semejantes (véase Gráfico 1), indicando que hay una estandarización en la construcción de los camélidos por parte de los grupos que ocuparon los distintos sitios o ejecutaron los paneles con representaciones rupestres en la microrregión de Guasapampa. En el estado actual de los estudios no es posible aún

Gráfico 1. Representatividad de los distintos cánones de camélidos identificados en cada una de las áreas Graph 1. Prevalence of different camelid canons identified in each area

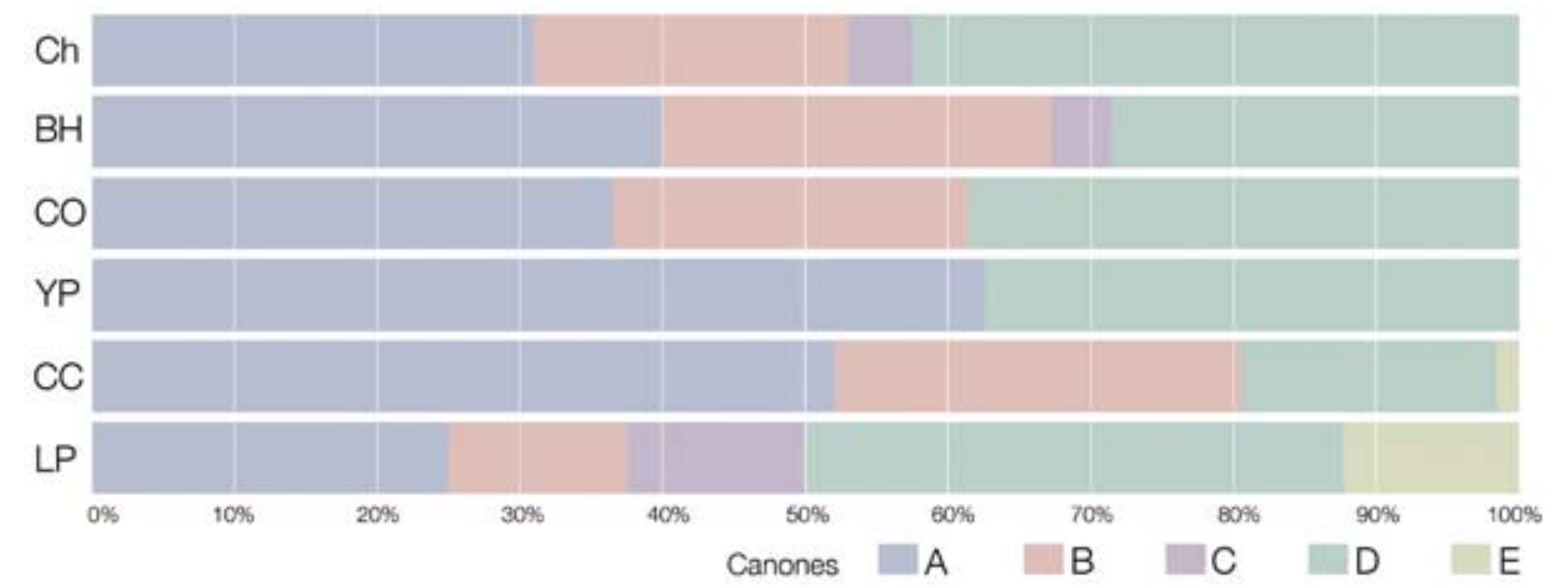


plantear que las diferencias de cánones observadas entre los paneles y las áreas estén respondiendo a diferencias de orden cronológico en su ejecución. Así, estas diferencias podrían dar cuenta de maneras particulares de ejecutar la figura del camélido que está circulando en el paisaje y que puede indicar el contacto entre grupos distintos, ya que, como mencionamos en párrafos anteriores, hay paneles en los que observamos más de un canon.

En este sentido, los sitios cuyas ocupaciones fueron fechadas en $1390 \pm 60 \mathrm{AP}(\mathrm{Ch} 2)$ y $390 \pm 60 \mathrm{AP}(\mathrm{CC} 3)$ conforman dos extremos del Período Prehispánico Tardío en la región de Sierras Centrales, y ambos presentan al menos tres o cuatro de los cánones identificados. Se reconocen los recaudos metodológicos al momento de relacionar la ejecución de los paneles con la ocupación, sin embargo, no se debe desestimar el hecho concreto respecto a que la ausencia de un contexto estratigráfico más antiguo, es decir, el período cazador-recolector que se extiende desde el 11.000 al 1500 AP, proporciona evidencia significativa para vincular las representaciones sólo con momentos tardíos.

Paralelamente, hemos documentado otros motivos que dan cuenta de una doble situación en tanto comparten rasgos comunes, pero su circulación es más acotada. En este sentido, son las figuras antropomorfas el ejemplo más claro, dado que muestran una estandarización o, en otros términos, los 11 motivos presentes en Guasapampa guardan el mismo patrón constructivo, el cual circula y conforma un código común en las definiciones de forma. Por su parte, tal vez las diferencias observadas en los rasgos de algunos motivos sean sólo consecuencia de "la mano" de los ejecutantes que actuaron en cada uno de los paneles. Asimismo, y de manera paralela, es factible concluir que presentan un entorno limitado de circulación, o sea, que la significación de este rasgo escapa al código común y compartido por todos lo que ocuparon Guasapampa. En este contexto las semejanzas percibidas en los patrones constructivos de algunos motivos puntuales como rheas y reptiles pueden estar dando cuenta de la especificidad de los vínculos entre los grupos que comparten la significación de la presencia de ese rasgo en el panel.

El estudio detallado de las asociaciones temáticas nos presenta un panorama similar al que describimos para las otras variables ya analizadas. En este sentido, hay diseños y asociaciones de motivos que circulan y se comparten entre y por los grupos que ocupan la microrregión (véase Tabla 2). En el universo total de temas identificados, resulta llamativa la alta frecuencia de las asociaciones de camélidos, dado que conforma el $22 \%(n=17)$, al tiempo que en algunos de estos lugares las escenas están constituidas y significadas de manera diferente, no sólo por la ejecución de representaciones particulares a cada grupo que habita ese lugar, sino por la combinación de motivos de diseños similares pero de maneras distintas. Sin embargo, un rasgo común a la mayoría de los paneles es que los "nuevos" motivos o temas se agregan a lo previo complementándolo o, de lo contrario, dan lugar a nuevas asociaciones, pero sólo en muy contadas ocasiones están ejecutados superponiéndose a lo preexistente.

Finalmente, la invisibilidad manifiesta en la mayoría de los paneles documentados en la microrregión, ya sea por su ubicación en el interior de tafones o por estar emplazados en abrigos que no posibilitan un acceso directo al panel y lo allí representado, permiten proponer que en Guasapampa sur la visibilidad de los paneles se restringe al ámbito de lo cotidiano, de lo doméstico y, por lo tanto, no interactúa con las personas que circulan por el paisaje en época estival, sino sólo con aquellos que ocupan y construyen ese lugar. Esto implica que la significación de los paneles se reduce a un ámbito que actúa directa y únicamente con un número reducido de personas y, en este sentido, conforma una materialidad cuya ejecución y observación está vinculada con las prácticas diarias a partir de las cuales se negocian, entre otros, los sentidos de pertenencia e identidad con el objetivo de asegurar la cohesión interna del grupo familiar, en las que el arte rupestre participa activamente.

\section{CONSIDERACIONES FINALES}

La información recuperada en la microrregión de Guasapampa nos permite identificar semejanzas y diferencias en las representaciones rupestres. Semejanzas que se traducen en una estandarización manifiesta en la selección de los motivos, los diseños compartidos e incluso en la manera de articular y asociarlos para la conformación de escenas y que daría cuenta de la existencia de un código "base" que es compartido y reconocido y que, probablemente, da cuenta de la integración de esas unidades a un grupo de mayor agregación o a los que los documentos españoles denominan como parcialidad. En tanto, las diferencias generan el marco en el cual se expresa lo específico del grupo familiar, a partir de la ejecución de motivos o asociaciones en los que la estandarización y significación común se quiebra para dar lugar a expresiones particulares, algunas de las cuales tienen una circulación muy acotada entre sitios o incluso, en algunos casos, constituyen elementos únicos en el paisaje. 
Sin embargo, y de manera paralela, tanto los rasgos compartidos como los específicos se constituyen como expresiones que se repiten a lo largo del tiempo, dado que lo "nuevo" se integra a lo ya ejecutado. Consideramos así que los lugares son reocupados por personas que reconocen un lazo de parentesco, una historia en común o identidades compartidas en base a algún principio de filiación entre quienes la ejecución de elementos únicos, pero estables, repetidos y significados de manera similar, constituyen rasgos que se incluyen a la memoria social como mecanismos de unidad (Lotman 1996), de integración y de reafirmación de las identidades.

Los fechados radiocarbónicos obtenidos en distintos sitios de la microrregión nos autorizan a plantear la existencia de prácticas sostenidas en el tiempo, prácticas que dan cuenta de la ocupación y la significación de Guasapampa sur, en tanto paisaje incorporado como destino estival dentro del circuito de movilidad estacional implementado por los grupos del Prehispánico Tardío de la provincia de Córdoba.

Toda esta información proporciona una línea de evidencia para sostener que existe en Guasapampa una doble estrategia en las dinámicas sociales. Por un lado una estrategia de afirmación de las identidades que asegura la cohesión interna de las unidades familiares, que ocupan y construyen los lugares a partir del reconocimiento, la ejecución y la combinación de rasgos simbólicos significados como únicos y particulares; por otro, y dado que estas particularidades se integran fundamentalmente al ámbito de lo privado, observamos una negación de las diferencias que forma parte de una estrategia que procura reducir el posible grado de conflicto entre los grupos que explotan el paisaje y que, en consecuencia, procura acrecentar la cooperación en la construcción de un entorno compartido.

RECONOCIMIENTOS Quisiera agradecer al Dr. Berberián y a la Dra. Bixio por la lectura crítica de este trabajo y por sus valiosos aportes. Agradezco también las sugerencias realizadas por los evaluadores. Asimismo, mi reconocimiento a Diego Rivero, Laura López, Gabriela Srur, Julia Re y Mariano Dantas por su colaboración en las tareas de campo. No quiero olvidar a Teresa y Niní quienes me brindaron su amistad. Esta investigación se realizó en el marco del proyecto "Proceso histórico y uso del espacio en los sectores de sierra y piedemonte-llanura de la provincia de Córdoba”, que contó con el respaldo de un subsidio (PIP 6519) otorgado por CONICET. Todo lo expuesto es de mi exclusiva responsabilidad.

\section{NOTAS}

${ }^{1}$ Entre los investigadores hay acuerdo respecto al análisis del panel como unidad mínima de análisis y que un sitio puede estar constituido por más de un panel, sin embargo, no hay acuerdo respecto a las distancias que dividen los sitios con arte entre sí (Gallardo
2001). Por lo tanto, la caracterización debe ser empírica y en base a criterios arbitrarios establecidos con parámetros especificados por el investigador. De esta manera, en este trabajo se considera que la distancia que debe mediar entre sitios con representaciones rupestres para ser considerados diferentes es de $10 \mathrm{~m}$.

2 Durante la década del setenta el área fue estudiada por Romero y colaboradores (1973). Aunque no hay un registro pormenorizado de los paneles, en esas publicaciones el autor menciona que documentó cerca de sesenta soportes con representaciones rupestres. Este dato específico nos ha enfrentado en el campo a una realidad preocupante, dado que nuestro registro es significativamente menor e implica que, por la explotación de las canteras de granito, mucha información ha desaparecido debido a la explotación indiscriminada de esta materia prima en las canteras al aire libre.

${ }^{3}$ Los equinos documentados en Charquina plantean una problemática diferente que escapa a los objetivos de este trabajo. Su presencia en el sur del valle de Guasapampa da cuenta del contacto de los grupos aborígenes con el conquistador y por lo tanto del principio de un proceso que paulatinamente transformó el modo de vida de las comunidades locales. En este sentido, la ejecución puede estar vinculada a los primeros momentos de la llegada del conquistador o por el contrario su escasa presencia puede estar inscrita en el marco de un sistema plenamente instaurado e impuesto por el español que generó cambios significativos en la estructura económica y social de los grupos aborígenes.

${ }^{4}$ La fecha obtenida de una muestra de carbón de YP1 de 1360 \pm 60 años AP (LP-1812) merece especial atención, dado que está asociada estratigráficamente a tiestos de cerámica y a fitolitos de maíz. Estos datos, junto a otros contextos fechados para el oeste de las Sierras Centrales $-1540 \pm 50$ años AP (LP 1658) y $1170 \pm 50$ años AP (LP1449) (Pastor 2007)-, están generando nueva evidencia que nos obliga a replantear los inicios del proceso regional que dio origen a la adopción de prácticas agrícolas de pequeña escala (Pastor 2007).

5 "[...] son todos unos... porque sienpre se an tratado por parientes debajo del apellido de Cantapas y ansi en sus fiestas y llantos se hallan los unos y los otros, e que estos yndios de Atanhenen van a senbrar juntos con los de Cantapas y los de Cantapas sienbran juntos a las chacaras de los indios de Atanhenen e que se tratan por una parzialidad y en sus guerras se ayudan los unos y los otros [...]". Archivo Histórico de Córdoba, Escribanía 1, Legajo 3, Expediente 9 (1590-91), citado por Piana de Cuestas (1992).

\section{REFERENCIAS}

AcuTo, F., 1999. Paisaje y dominación: la constitución del espacio social en el Imperio Inka. En Sed Non Satiata. Teoría social en la arqueología latinoamericana contemporánea, A. Zarankin \& F. Acuto, Eds., pp. 33-75. Buenos Aires: Ediciones Tridente.

Anschuetz K.; R. Wikshusen \& C. Scheick, 2001. An Archaeology of Landscapes: Perspectives and Directions. Journal of Archaeological Research 9 (2): 152-197. New York: Plenum Publishers.

Aschero, C., 1994. De cómo interactúan emplazamientos, conjuntos $\mathrm{y}$ temas. En Actas y Memorias del XI Congreso Nacional de Arqueología Argentina, Tomo xxv, pp. 23-35, Mendoza.

1996. ¿Adónde van esos guanacos? En Arqueología. Solo Patagonia, J. Gómez Otero, Ed., pp. 153-162. Ponencias de las Segundas Jornadas de Arqueología de la Patagonia, Centro Nacional Patagónico.

_2007. Iconos, huancas y complejidad en la Puna Sur Argentina. En Producción y circulación prebispánicas de bienes en el surandino, A. Nielsen, V. Seldes, M. Vázquez \& P. Mercolli, Comp., pp. 135-166. Córdoba: Editorial Brujas.

Augé, M., 1992. Los no lugares. Espacios del anonimato. Una antropología de la sobremodernidad. Barcelona: Editorial Gedisa. 
Barbero, J., 2006. Pensar juntos espacios y territorios. En (Des) territorialidades y (no) lugares. Procesos de configuración y transformación del espacio, D. Herrera Gómez \& C. Piazzini, Eds., pp. 17-28. Medellín: La Carreta Editores.

Bauman, Z., 2005. Identidad. Buenos Aires: Editorial Losada.

BENDER, B., 1993. Introduction. Landscape-Meaning and Action. En Landscape. Politics and Perspectives, B. Bender, Ed., pp. 1-17. Oxford: Berg.

Berberián, E.; S. Pastor; D. Rivero; M. Medina; A. Recalde; L. LÓPEZ \& F. ROLDÁN, 2008. Últimos avances de la investigación arqueológica en las Sierras de Córdoba. Comechingonia 11: 135-164, Córdoba.

Bixio, B. \& E. E. Berberián, 1984. Etnohistoria de la región de Potrero de Garay (provincia de Córdoba, Argentina). Comechingonia 3: 11-46, Córdoba

Criado Boado, F., 1995. The Visibility of the Archaeological Record and the Interpretation of Social Reality. En Finding meaning in the past, I. Hodder, M. Shanks, A. Alexandri, V. Buchli, J. Carmen, J. Last and G. Lucas, Eds., pp. 194-204. London: Routledge.

Criado Boado, F., 1996. En los bordes del paisaje. Capa. Del terreno al Espacio: planeamientos y perspectivas para la arqueología del paisaje 6: 1-63, Universidad de Santiago de Compostela.

Díaz Andreu, M. \& S. Lucy, 2005. Introduction. En Archaeology of Identity: Approaches to Gender, Age, Status, Ethnicity and Religion, M. Díaz Andreu, Ed., pp. 1-12. London: Routledge.

Demaio, P.; O. Karlin \& M. Medina, 2002. Árboles nativos del centro de la Argentina. Buenos Aires: L.O.L.A. (Literature of Latin American).

Gallardo, F., 2001. Arte rupestre y emplazamiento durante el Formativo Temprano en la cuenca del Río Salado (desierto de Atacama, norte de Chile). Boletín del Museo Chileno de Arte Precolombino 8: 88-97.

González Navarro, C., 1999. Espacios coloniales. Construcción social del espacio en las márgenes del Río Segundo-Córdoba (1573-1650). Córdoba: Centro de Estudios Históricos.

INGOLD, T., 1992. Culture and the Perception of the Environment. En Bush Base: Forest Farm. Culture, Environment and Development, E. Croll \& P. Parkin, Eds., pp. 39-56. London: Routledge.

- 1993. The temporality of the landscape. World Archaeology 25 (2): 152-165.

Jones, A., 1998. Where Eagles Dare. Landscape, Animals and the Neolithic of Orkney. Journal of Material Cultures 3 (3): 301324, London.
Lotman, I., 1996. El símbolo en el sistema de la cultura. En La semiosfera I. Semiótica de la cultura y del texto, D. Navarro, Ed., pp. 143-156. Madrid: Editorial Frónesis.

Martel, A. \& C. Aschero, 2007. Pastores en acción: imposición iconográfica versus autonomía temática. En Producción y circulación prebispánica de bienes en el surandino, A. Nielsen, V. Seldes, M. Vázquez \& P. Mercolli, Comp., pp. 329-349. Córdoba: Editorial Brujas.

PAstor, S., 2007 Ms. Arqueología del valle de Salsacate y pampas de altura adyacentes (Sierras Centrales de Argentina). Una aproximación a los procesos sociales del Período Prehispánico Tardío (900-1573 DC). Trabajo para optar al título de Doctor, Facultad de Ciencias Naturales y Museo, Universidad Nacional de La Plata, La Plata.

PiAna de Cuestas, J., 1992. Los indigenas de Córdoba bajo el régimen colonial (1570-1620). Córdoba: Dirección General de Publicaciones de la Universidad Nacional de Córdoba.

Piazzini, C., 2006. Arqueología, espacio y tiempo: una mirada desde Latinoamérica. Arqueología Sudamericana 2 (1): 3-25, Cauca, Colombia.

RECALDE, A., 2008a. Representaciones rupestres del Período Agroalfarero Tardío en el sector oeste de las Sierras Centrales (provincia de Córdoba). Arqueología 14: 239-249, Buenos Aires.

- 2008b. Representaciones rupestres y sitios de ocupación transitoria en el Período Agroalfarero Tardío: los casos de Charquina 2 y Cerco de la Cueva 3 en el Valle de Guasapampa (Córdoba). En Crónica sobre la Piedra. Arte rupestre de las Américas, M. Sepúlveda, L. Briones \& J. Chacama, Eds., pp: 181-192. Arica: Universidad de Tarapacá.

_ 2009. Movilidad estacional y representaciones rupestres. Primeras evidencias de ocupaciones estivales vinculadas con la explotación de ambientes chaqueños en las sierras de Córdoba. En Anales de Arqueología y Etnología. Mendoza: Universidad Nacional de Cuyo (en prensa).

Romero, C.; E. Argüello De Dorsch \& M. UAnini, 1973. El arte rupestre de Córdoba. Proyecciones. Edición especial en homenaje al IV Centenario de la Fundación de Córdoba, 8. Córdoba: Ika-Renault.

Santos Estévez, M. \& F. Criado Boado, 1998. Espacios rupestres: del panel al paisaje. Arqueología Espacial 19-20: 579-595, Teruel.

SoJA, E., 1985. The Spatiality of Social Live: Towards a Transformative Retheorization. En Social Relations and Spatial Structures, D. Gregory \& J. Urry, Eds., pp. 90-117. London: Macmillan. 